\title{
A Pilot Study Exploring the Impact of Interprofessional Simulation on Role Clarity and Student Readiness for Collaborative Clinical Practice
}

Shira Schecter Weiner

Touro College, shira.weiner4@touro.edu

Laura Hagan

Touro College, laura.hagan@touro.edu

Julie F. Kardachi

Touro College, julie.kardachi@touro.edu

Follow this and additional works at: https://nsuworks.nova.edu/ijahsp

Part of the Interprofessional Education Commons, Occupational Therapy Commons, Physical Therapy Commons, and the Physiotherapy Commons

\section{Recommended Citation}

Weiner SS, Hagan L, Kardachi JF. A Pilot Study Exploring the Impact of Interprofessional Simulation on Role Clarity and Student Readiness for Collaborative Clinical Practice. The Internet Journal of Allied Health Sciences and Practice. 2020 Jan 01;18(4), Article 18.

This Manuscript is brought to you for free and open access by the College of Health Care Sciences at NSUWorks. It has been accepted for inclusion in Internet Journal of Allied Health Sciences and Practice by an authorized editor of NSUWorks. For more information, please contact nsuworks@nova.edu. 


\title{
A Pilot Study Exploring the Impact of Interprofessional Simulation on Role Clarity and Student Readiness for Collaborative Clinical Practice
}

\begin{abstract}
Purpose: Interprofessional collaboration is recognized as a healthcare practice paradigm that may decrease overall costs and minimize errors. Yet it remains common for practitioners to provide care within silos, inadequately considering the impact of their decisions on other providers and overall costs, which ultimately may negatively impact the patient. Integrating interprofessional collaboration in school curricula can establish the importance of this approach to healthcare. For optimal efficacy, every professional in the healthcare team must recognize their unique role and the roles of others, to allow for seamless interprofessional collaboration. Simulation is a teaching tool that provides students with the opportunity to experience and reflect upon their responses to real-world clinical encounters in an environment that is safe to them and to patients. The purpose of this pilot study was to investigate the effect of interprofessional simulation on occupational therapy and physical therapy students' role clarity and perceived readiness for collaborative practice. Method: A mixed methods study design was used with occupational and physical therapy students matriculated in the same college. Two surveys were given to the participants pre- and post-interprofessional simulation: the Readiness for Interprofessional Learning Scale (RIPLS; evaluates student readiness for interprofessional learning) and the Interdisciplinary Education Perception Scale (IEPS; evaluates student perceptions of interprofessional training). Focus groups followed the interprofessional simulation to explore the subjects' experience. Results: Statistically significant changes were noted in the RIPLS pre-post simulation. Five themes emerged from the focus groups including: students value simulation; students value interprofessional education; interprofessional experience facilitates an understanding of role clarity; teamwork has value and challenges; and, students value providing patient centered care. Conclusion: Simulation is a teaching resource that may prepare occupational therapy and physical therapy students for interprofessional collaboration in patient care. The results of this study can inform interprofessional curricular development for both occupational therapy and physical therapy programs.
\end{abstract}

\section{Author Bio(s)}

Shira Schecter Weiner, PhD, PT, CIE, is a Professor in the Doctor of Physical Therapy Program at Touro College. Dr. Weiner has been a physical therapist for 37 years and with 20 years of experience in research in research and academia.

Laura Hagan PT, PhD, DPT, MS is the associate director and instructor for the Doctor of Physical Therapy Program at Touro College. Dr. Hagan has been a practicing physical therapist for the past 19 years and has 15 years of experience in academia and research.

Julie Kardachi OTD, OTR/L, CLA is the Associate Chair of Academic Coordination and Associate Professor in the Occupational Therapy Program at Touro College. Dr. Kardachi has been an occupational therapist for 38 years and has 19 years of experience in academia and research.

\section{Acknowledgements}

This study was funded by the Presidential Research Development Grant, Touro College, New York, NY. 


\title{
IJAHSP \\ The Internet Journal of Allied Health Sciences and Practice
}

Dedicated to allied health professional practice and education

Vol. 18 No. 4 ISSN 1540-580X

\section{A Pilot Study Exploring the Impact of Interprofessional Simulation on Role Clarity and Student Readiness for Collaborative Clinical Practice}

\author{
Shira Schecter Weiner \\ Laura Hagan \\ Julie F. Kardachi \\ Touro College \\ United States
}

\begin{abstract}
Purpose: Interprofessional collaboration is recognized as a healthcare practice paradigm that may decrease overall costs and minimize errors. Yet it remains common for practitioners to provide care within silos, inadequately considering the impact of their decisions on other providers and overall costs, which ultimately may negatively impact the patient. Integrating interprofessional collaboration in school curricula can establish the importance of this approach to healthcare. For optimal efficacy, every professional in the healthcare team must recognize their unique role and the roles of others, to allow for seamless interprofessional collaboration. Simulation is a teaching tool that provides students with the opportunity to experience and reflect upon their responses to real-world clinical encounters in an environment that is safe to them and to patients. The purpose of this pilot study was to investigate the effect of interprofessional simulation on occupational therapy and physical therapy students' role clarity and perceived readiness for collaborative practice. Method: A mixed methods study design was used with occupational and physical therapy students matriculated in the same college. Two surveys were given to the participants pre- and post-interprofessional simulation: the Readiness for Interprofessional Learning Scale (RIPLS; evaluates student readiness for interprofessional learning) and the Interdisciplinary Education Perception Scale (IEPS; evaluates student perceptions of interprofessional training). Focus groups followed the interprofessional simulation to explore the subjects' experience. Results: Statistically significant changes were noted in the RIPLS pre-post simulation. Five themes emerged from the focus groups including: students value simulation; students value interprofessional education; interprofessional experience facilitates an understanding of role clarity; teamwork has value and challenges; and, students value providing patient centered care. Conclusion: Simulation is a teaching resource that may prepare occupational therapy and physical therapy students for interprofessional collaboration in patient care. The results of this study can inform interprofessional curricular development for both occupational therapy and physical therapy programs.
\end{abstract}

Keywords: mixed methods study design, physical therapy, occupational therapy, interprofessional collaboration, simulation 


\section{INTRODUCTION}

Current healthcare systems demand high-value care that maximizes patient outcomes while minimizing expenditure. Despite this, healthcare costs continue to rise in the United States without concomitant improvements in outcomes, resulting in a net low-value system. ${ }^{1}$ Therefore, all involved, including clinical training programs, providers, insurers and administrators, must continually rethink current paradigms and adapt to meet societal needs. One area cited as contributing to low-value care is that of work silos. ${ }^{2}$ The concept of work silos in healthcare can be defined as each subspecialty working autonomously to achieve goals without consideration of the impact on other providers, overall healthcare delivery, and most importantly, patient outcomes. ${ }^{3}$ Recognizing the need to break down silos in professional education is the first step toward improving our universal efforts to challenge the status quo. With faculty integration of student interprofessional (IP) collaboration at the academic level in health science programs, students should recognize it as the standard of practice. ${ }^{4}$ Furthermore, clinical academic programs are required by accrediting bodies to integrate interprofessional education (IPE) into existing curricula, yet barriers to IP training persist for various reasons, including scheduling challenges and distinct discipline cultures. ${ }^{5-7}$

Collaborative approaches to patient care are valued by today's standards and are associated with improved outcomes. . $^{8-10}$ While the evidence suggests that working in silos is detrimental, and that an IP approach to care is valued, there is limited evidence clearly defining effective collaborative teams for specific patient groups. ${ }^{11-13}$ Occupational therapy (OT) and physical therapy (PT) are distinct professions, each with their own scope of practice; yet, approaches to patient care are often based on overlapping and complimentary problem lists and goals. ${ }^{14,15}$ As such, a collaborative approach to care between these two professions may yield improved outcomes such as decreased length of hospital stay. ${ }^{16}$

The current landscape of healthcare necessitates a shift in clinical training to best prepare novice practitioners. ${ }^{17}$ Simulation, "a bridge between classroom learning and real-life experience," is an educational modality that prepares clinical trainees for patient care.18 Using simulation allows educators to challenge students to perform various technical and non-technical skills without risk to themselves or their patients, and conduct formative assessments that may be used to foster student competence. ${ }^{19}$ Cases are developed and reviewed by interprofessional clinical faculty for face validity, to replicate all aspects of a clinical encounter. Students are asked to perform various assessments and procedures, using mannequins or standardized patients to represent the patient. Interprofessional simulation in clinical training programs has been shown to facilitate learning, skill acquisition, and self-efficacy, yet research is lacking for its utility in OT and PT education. ${ }^{20,21}$ Studies are needed to explore approaches to integrating IP simulation in health science curricula to enhance student training and preparedness for clinical practice. The purpose of this pilot study is to investigate the effect of IP simulation on role clarity of OT and PT students' and their perceived readiness for collaborative learning, which in turn may prepare students for collaborative patient care. The research question is: what is the effect of IP simulation on OT and PT students' role clarity and perceived readiness for collaborative learning?

\section{MATERIAL AND METHODS}

This study was implemented in a low fidelity simulation laboratory in an urban school of health sciences setting. The project was reviewed by the institution's IRB and received exempt status approval. Participants were recruited via email from the OT and PT programs, both of which are six semesters. Participants were in their 4th semester (OT) and 5th semester (PT) of schooling, and both groups had experienced clinical placements.

In clinical settings, OT and PT often work together. As such, we consider the inclusion of these two professions a purposeful methodological decision. After consenting, subjects completed two validated questionnaires: The Readiness for Interprofessional Learning Scale (RIPLS) (Appendix A) and the Interdisciplinary Education Perception Scale (IEPS) (Appendix B). The RIPLS is a 19-question scale developed to explore healthcare student readiness for IP learning. ${ }^{22,23}$ The instrument is subdivided into four subscales: teamwork and collaboration, negative professional identity, positive professional identity, and roles and responsibilities. All questions are answered using a five-point Likert scale ( $1=$ strongly disagree to $5=$ =strongly agree) with reverse scoring for negative professional identity. Higher scores suggest a student is more prepared to actively engage in meaningful learning with students from other professions. The IEPS is an 18-question instrument used to evaluate student perceptions of an IP training experience. The questionnaire includes four subscales: competence and autonomy, perceived need for cooperation, perception of actual cooperation, and understanding others value. It uses a six-point Likert scale (1=strongly disagree to 6=strongly agree), with higher scores suggesting a more positive view on IP collaboration. ${ }^{24}$ Both psychometrically sound instruments are used in studies assessing student response to an IP experience and have been shown to be relatively equal in their ability to detect changes. 25,26

After completion of the baseline questionnaires, each OT-PT participant pair collaborated in a simulated patient scenario. Designing the clinical scenario involved multiple steps aimed at creating cases that reflected the intended competencies and taking into 
consideration the tools to assess those competencies. ${ }^{27}$ The case involved a patient with a cerebral vascular accident and was relevant to the practice of both OT and PT. Participants were briefed before the encounter, provided with a medical chart, and asked to co-evaluate the patient's functional status. Each simulated patient was portrayed by a single standardized patient who was carefully trained by the faculty to represent an actual patient in a convincing and consistent manner. ${ }^{28}$

Simulations were simultaneously observed by the investigators and recorded using SimCapture (B-line Medical, Washington, DC). Following the simulation, the participants actively engaged in the debriefing process lead by the investigators to foster reflection on the experience including the nature of the collaboration and role clarity. The standardized patient participated during this process and gave constructive feedback to the participants. Debriefing is recognized as an integral component of the simulated experience, where students may explore, in a nonjudgmental manner, the process by which decisions were made during the simulated case. ${ }^{29}$ Immediately after the debriefing, the participants repeated the same questionnaires completed at baseline (Appendix A and Appendix B Questionnaires).

The RIPLS and IEPS sub-scores were calculated based on the published methodology. ${ }^{30,31}$ Each sub-score value for all subjects, and for each student group was compared pre-post simulation to determine if the experience had an effect on student readiness or perceptions of IP training. In addition, changes in RIPLS and IEPS sub-scores were computed for each participant by subtracting the pre-simulation value from the post-simulation one. For this analysis we directly compared OT to PT student participants to evaluate if the response to the simulation varied between the different student groups.

Following the completion of all simulations and questionnaires, participants were invited via email to participate in a focus group. The purpose of a focus group is to understand the perspective of a particular group of individuals through discussion. ${ }^{32}$ The researchers used focus groups to explore the experience of the participants in a comfortable setting with peers that allowed them to freely react to one another's comments and to facilitate conversation. An interview guide was used to keep the conversation centered on the research question (Appendix C: Interview guide). The focus groups were conducted using an online meeting platform to facilitate ease of participation. The focus groups were led by one of the researchers, while the other researchers provided ancillary support.

Each focus group was approximately one hour long and was video recorded. The audio files from the recordings were transcribed by a third party and verified by two researchers (LH, JK) for accuracy. Transcripts were imported into NVivo (QSR International Pty Ltd, Version 11), a qualitative data software program. The program was used to manage the data analysis and document field notes. Field notes, or the recording of the researcher's thoughts and observations, are commonly used in qualitative data analysis and were integrated in the data analysis process for this study. ${ }^{33}$ As the researcher reviewed the video recordings along with the transcripts and engaged in the coding process, field notes were used to document personal thoughts, reflections, and observations. These field notes were referred to when synthesizing the data.

Transcripts were initially coded by two of the three researchers independently $(\mathrm{LH}, \mathrm{JK})$. The investigators used constant comparison, a process of analyzing data that involves identifying salient ideas within the data and grouping them under a description, or code, based on commonality. As codes were developed, they were compared, and then consolidated, eliminated or left as a unique code. ${ }^{34}$ The two researchers engaged in an initial coding process individually and developed their own set of codes based on the data. After each researcher completed their initial analysis, they discussed their findings and came to consensus on themes. Upon completion of the analysis, the third researcher (SSW) served as a peer debriefer who reviewed the transcripts and compared them to the analysis looking for biases or alternative explanations. ${ }^{35}$ After the peer debriefing, the third researcher agreed with the themes and confirmed that they were grounded in the data.

A member check was used to enhance the trustworthiness of the findings. Member checking provides the researcher with an opportunity to correct errors and confirm data by presenting the findings to the participants. ${ }^{34}$ The researchers' qualitative analysis was emailed to the participants with a request to review the findings for authenticity. All of the responding participants agreed with the qualitative analysis and reported that it reflected what was expressed in the focus groups.

\section{RESULTS}

\section{Quantitative Data}

Table 1 provides information about the participants and the makeup of each of the two focus groups. Dependent t-tests showed that there were no statistically significant changes in the IEPS (pre-post simulation). However, pre-post simulation changes were noted on two of the RIPLS subscales; negative professional identity ("I don't want to waste time learning with other health and social care students / professionals") ( $p=0.03)$ and positive professional identity ("Shared learning with other health and social care 
professionals will help me to communicate better with patients and other professionals") $(\mathrm{p}=0.01)$ both changed significantly postsimulation.

Table 1. Demographic information of participants and group assignment

\begin{tabular}{|c|c|c|c|c|}
\hline Speaker & Gender & Profession & Year of Study & Simulation Assignment \\
\hline \multicolumn{5}{|c|}{ Focus Group 1 } \\
\hline S1 & F & OT & Year 2 & Simulation 1 \\
\hline S2 & F & OT & Year 2 & Simulation 2 \\
\hline S3 & M & PT & Year 3 & Simulation 2 \\
\hline S4 & M & PT & Year 3 & Simulation 1 \\
\hline \multicolumn{5}{|c|}{ Focus Group 2 } \\
\hline S5 & F & PT & Year 3 & Simulation 3 \\
\hline S6 & F & PT & Year 3 & Simulation 4 \\
\hline S7 & F & PT & Year 3 & Simulation 5 \\
\hline S8 & F & OT & Year 2 & Simulation 4 \\
\hline S9 & F & OT & Year 2 & Simulation 3 \\
\hline S10 & F & OT & Year 2 & Simulation 5 \\
\hline
\end{tabular}

Changes in IEPS and RIPLS subscales pre-simulation versus post-simulation were compared between groups using independentsample t-tests. The results showed no significant changes in IEPS or RIPLS scores between the OT and PT student groups.

\section{Qualitative Data}

The following 5 themes emerged from the qualitative analysis:

- Students value simulation

- Students value interprofessional education

- Interprofessional experience facilitates an understanding of role clarity

- Teamwork has value and challenges

- Students value providing patient centered care

\section{Students Value Simulation}

The student participants expressed a positive outlook on the simulated learning experience which included faculty and standardized patient feedback. They felt that it made the learning of technical and non-technical skills "real" and challenged their critical thinking abilities. Student response was not limited to the use of simulation for IPE. They saw the value in this type of training across the curriculum and felt that it should be incorporated into their professional programs.

- And just the whole setting, it was kind of real... it was more concrete than abstract. In the classroom, it's very, okay, so think of this case scenario that we're giving you and come up with it. In the simulated lab, you had the patient there, and you were able to actually do the things with them. So it made the learning experience, I think, had so much more essence to it. You were able to learn and actually afterwards think about what you did and what you did wrong. And then even when we went over it after, I felt like I learned so much. (S4, OT)

- From getting feedback after being watched for the simulation, is that when you're in the clinic the only feedback you get is from your clinical instructor. And your clinical instructor may or may not be good at giving constructive feedback [laughter]. So in a way it's nice to kind of get that feedback from someone who can give you constructive feedback or in way knows a little bit more. And that's something I think is very valuable and you can carry with you. (S9, OT)

- I think the fact that you don't really know what the teacher is looking from, like when you take a test, you know the answer that they're looking for, I felt confused as to what you guys were looking for in the sim. And you can't make eye contact with a person, so it's sort of just testing your ability to go with the flow and go with like what's given to you. It also really mimics real life a little bit more than an exam does, so I like that challenge also. (S4, PT)

\section{Students Value Interprofessional Education}

The participants in this study saw great value in incorporating IPE into their program's curriculum. After their simulated IPE experience, they expressed that working with another member of the healthcare team gave them the opportunity to develop a deeper understanding of the other's role. In addition, they perceived that this experience prepared them for IP practice in the clinic. 
Students' feedback on IPE was not limited to the use of simulation. They saw value in threading IP care throughout their professional education.

- I feel like nothing would replace the clinic experience and learning straight from there, that's very true. And until you actually see what they do, you won't have an idea of it. But I feel like interprofessional is such a big thing in healthcare now, you're guaranteed to have to know it in the hospital, and you shouldn't go into the clinic without having an idea what other professionals do. I feel like we should definitely know their scope, and have an idea what other students, what their input is before we go into the clinic. (S5, PT)

- I think the collaboration part was interesting for me to see....It was nice to see how we work together professionally. But from an educational level, I thought it was interesting to see what I know, what I could bring to the table. I guess in this situation also where it's OT and PT. I guess they work together but they're also separate. (S2, OT)

- ...we'll have a case study and then all of a sudden it will be like, "And then we could just throw a couple of things out there that OT could deal with," as opposed to really going in-depth about anything...We spent the entire semester working on a [paper] case. So it would have been interesting to also have OTs there telling us what they would do, and how they would treat, and maybe trying to come up with a treatment session together. (S6, PT)

- So when we were doing case studies or anything like that sort, I feel like most of the time we learn it from the perspective of we're kind of in the center, we're in the center of this practice and this is our duty to the patient. Yeah. We'll get a mention of speech or a PT. I guess I have an okay knowledge about what PTs do too, but it's different when you actually step into a room where you're physically working together, and you have to adjust yourself. (S8, OT)

\section{Interprofessional Experience Facilitates an Understanding of Role Clarity}

Engaging in the IP patient scenario challenged students to reflect on their own professional role as well as the role of the other clinician. Students expressed a sense of awareness of their scope of practice and the unique perspective they bring to the team. It was also clear that the students became more cognizant of the role of the other profession and were mindful of the additive value of collaboration. They recognized that there was overlap in the OT and PT roles, but they also acknowledged when the expertise of the other professional was indicated.

- You know how there's the whole thing, how all PTs can do basically everything that OTs do, right? There's that. So it just feels good to know that right away when it came to the dressing and the actual activities of daily living, I was able to say, "Oh, we do this." And it was like, "Hey, so we are separate," and of course, we have a lot that we do collaborate on, and it's great, but we each have our separate roles too. So that's a good feeling. Occupational therapy has its own mission I guess, what we want to do, and then PTs have their own also, but we can also come together and work together. (S1, OT)

- And it [IPE simulation] made me realize how in way I was uncertain when exactly what my role was. In a way though it was a good experience to see, "Here you go. You're paired with another person. How are you going to collaborate? How are you going to be put together? How are you going to communicate together?" So I feel that was a really good experience in terms of kind of an impromptu, "Let's see how you're doing with interacting with another professional, for the benefit of the client." And it kind of brings out-- helps you I guess realize for yourself how would you do in a situation like that if it ever comes up. (S9, OT)

- I wasn't giving OT their due, sort of I was definitely conscious of that, and then looking at the chart, it was like, "Yeah, dressing and toileting and things like that. That's not...could I have figured it out if I was the only one there... Maybe. But it's definitely not my purview, so I was like, "Okay. Perfect. That's definitely something the OT is going to be more on top of, and so we both have - it was sort of easy to see how most things could be split up. (S3, PT)

\section{Teamwork Has Value and Challenges}

The OT and PT teams recognized the need to work as a team to achieve a common goal and effectively and efficiently treat the patient. Pre-planning the treatment session and communicating with one another to support collaboration was acknowledged as important for establishing the plan of care. They had an appreciation for shared decision making and valued each other's input. During the simulations, the researchers observed respectful communication between the participants who allowed the expression of thoughts without interruption or undermining each other when speaking to the patient.

- I think the main aspect that was good about it was that we were able to talk together and set up how we were going to approach the situation because if I was by myself, obviously, I would have had to have done everything. Whereas having a team, sort of go in and evaluate the patient, it was more of like we were able to establish kind of a plan together and then go from there versus doing it by yourself. (S1, OT) 
- Yeah, I liked that because there were things that clearly overlapped, either of us could have done it... And then there was things like, "Okay. Maybe you do this, and you do that" and sort of handled that. Even before we saw a patient, we were able to sort of know that. (S4, PT)

- I mean just to be able to talk out your thoughts with someone else who's going in it with you even if I were going in with 2 PTs to treat one person. So with [the OT student], we're like, "Okay, that makes sense, that makes sense, and this is what we're going to do". And it felt pretty great. (S2, PT)

Students wanted to respect the other profession's role while trying to preserve the patient's confidence in them but working as a team was not always as seamless as they had hoped. At times students found themselves in an "awkward dance" with each other. This was also observed by the researchers during the simulated patient encounter. Students appeared unsure at times. This was evident in moments of silence and glances of what appeared to be confusion between the two students. Their body language mimicked the "awkward dance". Some students would take a step forward towards the patient and then back, uncertain if it was their time to engage with the patient. This prompted them to reflect on their experience and determine how they could improve their teamwork in the future.

- I felt that we had a little bit of tough time at first, and we were kind of trying to dance between each other, and it was a little bit of an awkward dance. So that was more just difficult and then we didn't fully understand each other's roles, and when it was the right time to come in. So it actually turned out to be a little uncomfortable for the patient especially. So that was kind of hard and I feel like had we had more discussion and known what each other wanted to do...I think that would have helped. (S6, PT)

- "Should I go next? Should you go next?" Kind of a back and forth of, "Do you want to take this? Do I want to take this?" We didn't really have so much of a system or an organization. (S7, PT)

\section{Students Value Providing Patient Centered Care}

Participants expressed respect for the patient and concern for the patient's perception of the collaborative approach to care. They identified that working in silos creates redundancies that could negatively impact care and the patient's confidence in their providers, recognizing teamwork as a means to efficient and comprehensive treatment. Despite any awkwardness they may have experienced during their simulated co-treatment, the students were aware of the patient's perspective and wanted to shield them from any impression of incompetence. As a team they wanted to ensure that the patient felt cared for.

- I agree with [the OT student] that from both the evaluation standpoint of, number one, just putting two heads together from two different perspectives, you can get a more holistic or a better evaluation. I totally agree that it would make a patient feel much more cared for, or better cared for, or that we're collaborating on their care versus like, right, if you have four different people coming in and asking a lot of overlapping questions, four different specialties, then you'll feel ...are you not all treating me? So that collaboration can be very valuable in terms of how the patient perceives it. (S3, PT)

- So we didn't want the patient to be [feel] awkward, so we would just kind of go with it, while kind of giving each other a chance to get our main goals in. Just trying to make the patient more comfortable than anything. To make sure [the patient] didn't realize that we didn't know who should go next, and what we should do next. (S5, PT)

- Yeah, I mean, I guess it could be overbearing ..., maybe they're [OT and PT] not working well together, and they just have their own goal in mind. But if it's two professionals working with the same goal in mind and they know that, and they know exactly what they're trying to do and how they're trying to accommodate the patient, then ... that makes them [the patient] feel safer. (S8, OT)

\section{DISCUSSION}

We conducted a pilot study to test a methodology prior to integrating OT and PT IPE into the existing curriculum. The challenge of IP collaboration in clinical practice to improve patient outcomes is well documented, as are efforts to remediate this. ${ }^{36}$ Clinical programs are required to integrate IPE into existing curricula., 5 The question remains, how effective are these IPE initiatives? This study aimed to test the utility of using simulation for IP training based on simulations' effectiveness in clinical training programs. The long-term goal is to use the results of this pilot study to refine the methodology for developing curricular changes. The authors' position is that immersing students in IP collaboration using simulation is a direct approach that may facilitate a seamless transition to IP clinical practice.

This pilot study explored the effects of an IP simulation on OT and PT students by assessing pre-post changes using the IEPS and RIPLS instruments and by investigating student perceptions through focus groups. The IEPS and the RIPLS are composed of 
multiple subscales, yet these results showed significant changes in two subscales of the RIPLS; 'negative professional identity' and 'positive professional identity'. This suggests that after exposure to IP simulation, the students had an increased appreciation for the value IP training.

The case developed for the simulation was carefully reviewed for face validity by both OT and PT clinicians prior to implementation. The consensus was that the case was appropriate for both student groups, would challenge each professional group individually, as well as challenge them to work interprofessionally. It should be noted that the case was designed to promote IP cooperation and dialogue while omitting the need for complex clinical decision-making by either student group. Despite this, following the exposure, there was some concern by the OT faculty that the OT students were not equally challenged while executing the case. Therefore, in future studies of IP simulation more robust efforts are needed in the design and case validation prior to implementation.

A strength of this pilot study was the mixed methods design. The use of focus groups to extract student experiences provide key data that lent deeper insights into the impact of this IP experience than could be gleaned from the small quantitative data set. For example, of the five themes that emerged from student interviews, the theme 'Students value interprofessional education' confirms the quantitative data findings related to professional identity.

The other themes resulting from the focus group discussions provide meaningful insight into the student experience with IP simulation training. Once again, these findings, which may inform curricular development, could not be deduced from the surveys alone. Students clearly recognized the benefit of integrating simulation training and IP collaboration into the academic experience. They also recognized how such training may foster the ability to develop the important skill of working as part of a team. Lastly, a focus on patient centeredness, a hallmark of excellent care directly associated with improved outcomes, ${ }^{37}$ did not emerge in the surveys, yet was clearly described by the subjects.

Students described their personal experiences in the clinic with IP care, which, although not directly related to the aim of the study, the authors felt was worth mentioning. In some cases, there seems to be inconsistency between what the students are taught about IP practice in the classroom and what they experience in the clinic. Students were heavily influenced by the culture of the clinic even if that influence contradicted professional standards. This echoes the literature on the impact of the hidden curriculum and its effect on the development of healthcare providers. ${ }^{38-40}$ Students seem to follow the culture of their clinical placement as opposed to that of their school and doubted the appropriateness of challenging or even questioning the clinical instructor. For those students who engaged in IP practice, a sense of enhanced satisfaction with patient care was expressed. Future research on the influence of clinic culture on student development of IP care is needed.

\section{Limitations}

While there are limitations worth noting, it is important to recognize that this was a pilot study intended to test and refine a methodology. As a pilot, a small sample was included, yet this limits the likelihood of sufficient power to detect pre-post changes. Subject recruitment was challenging due to disparate schedules between our sample student groups. Both groups cycle between classroom and clinical placement. As such there were limited periods in which both groups were available for participation as subjects. In addition, the time commitment for the participants was considerable, which challenged our recruitment. Due to this limitation, a financial incentive was added, with IRB approval, after the start of data collection.

There is literature to suggest that the IEPS and RIPLS may lack discriminate reliability. ${ }^{26}$ Therefore, in future IPE studies, other instruments may be needed if detecting subtle between-group differences is of interest. No other professions were integrated into this IP experience, which imposes certain limitations to the student experience. The case used in the simulation represented a typical patient that students from either professional group would likely encounter during clinical practice, however, once implemented, limits of the case became apparent. The simulation literature lacks a standardized framework for how to effectively design an IP simulated case to challenge the outcomes of interest. Therefore, future efforts are needed to better understand simulation-case-study design and ways to similarly challenge different professions and evoke perspectives on IP collaboration.

\section{CONCLUSION}

Simulation is a teaching resource that may foster improved appreciation for IP collaboration in patient care. This was a pilot study assessing the impact of IP simulation on role clarity and readiness for IP collaboration among OT and PT students. Using a mixed methods design provided insights into the subjects' experiences. Methodological strengths and weaknesses are highlighted and can provide useful information to other researchers when designing studies on this topic. The results of this study can inform IP curricular development for both OT and PT programs, and further investigation into the utility of simulation for IP education. 


\section{CONFLICTS OF INTEREST}

The authors report no conflicts of interest in this work.

\section{ACKNOWLEDGMENTS}

This study was funded by the Presidential Research Development Grant, Touro College, New York, NY

\section{REFERENCES}

1. Burke LA, Ryan AM. The complex relationship between cost and quality in US health care. Virtual Mentor. 2014;16(2):124130. doi: 10.1001/virtualmentor.2014.16.02.pfor1-1402. [PMID: 24553333]

2. Ginsburg PB. High and rising health care costs. The synthesis project. Research Synthesis Report. 2008(16). [PMID: 22052035]

3. Reams K, Little A. 3 ways disrupting healthcare silos helps achieve triple aim goals. Becker's Hospital Review Web site. https://www.beckershospitalreview.com/patient-flow/3-ways-disrupting-healthcare-silos-helps-achieve-triple-aim-goals.html. Updated 2017.

4. Thomas A, Saroyan A, Snider LM. Evidence-based practice behaviours: A comparison amongst occupational therapy students and clinicians. Can J Occup Ther. 2012;79(2):96-107. doi: 10.2182/cjot.2012.79.2.5. [PMID: 22667018]

5. Commission on Accreditation in Physical Therapy Education (CAPTE) Standards and required elements for accreditation of physical therapist education programs. 2017. Available from: http://www.capteonline.org/uploadedFiles/CAPTEorg/About_CAPTE/Resources/Accreditation_Handbook/CAPTE_PTStand ardsEvidence.pdf

6. Accreditation Council for Occupational Therapy Education (ACOTE) Standards and interpretive guide. 2018. Available from: https://www.aota.org/ /media/Corporate/Files/EducationCareers/Accredit/Standards/2011-Standards-and-Interpretive-Guide

7. Olenick M, Flowers M, Muñecas T, Maltseva T. Positive and negative factors that influence health care faculty intent to engage in interprofessional education (IPE). Healthcare (Basel). 2019;7(1). [PMID: 30781453]

8. Matzke GR, Moczygemba LR, Williams KJ, Lee WT. Impact of a pharmacist-physician collaborative care model on patient outcomes and health services utilization. Am J Health Syst Pharm. 2018;75(14):1039-1047. [PMID: 29789318]

9. Wood JG. Collaborative care on the stroke unit: A cross-sectional outcomes study. J Neurosci Nurs. 2016;48(5):E2-E11. [PMID: 27579967]

10. Durojaiye $A B$, Levin $S$, Toerper M, Kharrazi $H$, Lehmann HP, Gurses AP. Evaluation of multidisciplinary collaboration in pediatric trauma care using EHR data. J Am Med Inform Assoc. 2019;26(6):506-515. [PMID: 30889243]

11. Ka C, A W, C N. We have all been working in our own little silos forever: Exploring a cross-sector response to child maltreatment. Acad Pediatr. 2019;20(1):46-54 PMID:31185309

12. Titzer JL, Swenty CF, Mustata Wilson G. Interprofessional education: Lessons learned from conducting an electronic health record assignment. J Interprof Care. 2015;29(6):536-540 PMID: 25955409

13. Al Maini M, Al Weshahi Y, Foster HE, et al. A global perspective on the challenges and opportunities in learning about rheumatic and musculoskeletal diseases in undergraduate medical education: White paper by the world forum on rheumatic and musculoskeletal diseases (WFRMD). Clin Rheumatol. 2020;39(3):627-642. [PMID: 31127461]

14. What is occupational therapy? American Occupational Therapy Association Web site. https://www.aota.org/ConferenceEvents/OTMonth/what-is-OT.aspx. Updated 2019.

15. The physical therapist scope of practice. American Physical Therapy Association Web site. http://www.apta.org/scopeofpractice/. Updated 2019.

16. Pape, B., Thiessen, P.S., Jakobsen, F., \& Hansen, T.B. Interprofessional collaboration may pay off: Introducing a collaborative approach in an orthopaedic ward. J Interprof Care. 2013;27(6):496-500. doi: 10.3109/13561820.2013.808611. [PMID: 23805863]

17. Deusinger SS, Crowner BE, Burlis TL, Stith JS. Meeting contemporary expectations for physical therapists: Imperatives, challenges, and proposed solutions for professional education. J Phys Ther Educ. 2014;28:56-61. doi: 10.1097/00001416201400001-00010.

18. Society for Simulation in Healthcare [Internet]. About Simulation. Available from https://www.ssih.org/About-SSH/AboutSimulation

19. Mori B, Carnahan H, Herold J. Use of simulation learning experiences in physical therapy entry-to-practice curricula: A systematic review. Physiother Can. 2015;67(2):194-202. doi: 10.3138/ptc.2014-40E. [PMID: 25931672]

20. Egenberg S, Øian P, Eggebø TM, Arsenovic MG, Bru LE. Changes in self-efficacy, collective efficacy and patient outcome following interprofessional simulation training on postpartum haemorrhage. J Clin Nurs. 2017;26(19-20):3174. [PMID: 27874995] 
21. Gilfoyle E, Koot DA, Annear JC, et al. Improved clinical performance and teamwork of pediatric interprofessional resuscitation teams with a simulation-based educational intervention. Pediatric critical care medicine: a journal of the Society of Critical Care Medicine and the World Federation of Pediatric Intensive and Critical Care Societies. 2017;18(2):e62. [PMID: 28157808]

22. Parsell G, Bligh J. The development of a questionnaire to assess the readiness of health care students for interprofessional learning (RIPLS). Med Educ. 1999;33(2):95-100. [PMID: 10211258]

23. Reid R, Bruce $D$, Allstaff $K$, McLernon D. Validating the readiness for interprofessional learning scale (RIPLS) in the postgraduate context: Are health care professionals ready for IPL? Med Educ. 2006;40(5):415-422. doi: 10.1111/j.13652929.2006.02442.x. [PMID: 16635120]

24. Luecht RM, Madsen MK, Taugher MP, Petterson BJ. Assessing professional perceptions: Design and validation of an interdisciplinary education perception scale. J Allied Health. 1990;19(2):181. [PMID: 2365636]

25. McFadyen AK, Webster V, Strachan K, Figgins E, Brown H, McKechnie J. The readiness for interprofessional learning scale: A possible more stable sub-scale model for the original version of RIPLS. J Interprof Care. 2005;19(6):595-603. doi: 10.1080/13561820500430157. [PMID: 16373215]

26. Lie DA, Fung CC, Trial J, Lohenry K. A comparison of two scales for assessing health professional students' attitude toward interprofessional learning. Med Educ Online. 2013;18:21885. [PMID: 24300749]

27. O'Brien JE, Hagler D, Thompson MS. Designing simulation scenarios to support performance assessment validity. J Contin Educ Nurs. 2015;46(11):492-498 PMID: 26509401

28. Society for Simulation in Healthcare [Internet]. Healthcare Simulation Dictionary. Available from https://www.ssih.org/Dictionary

29. Smith JR, Cole FS. Patient safety: Effective interdisciplinary teamwork through simulation and debriefing in the neonatal ICU. Crit Care Nurs Clin North Am. 2009;21(2):163. [PMID: 19460662]

30. Al-Qahtani MF. Measuring healthcare students' attitudes toward interprofessional education. J Taibah Univ Med Sci. 2006;11(6):579-585.

31. Hawk C, Buckwalter K, Byrd L, Cigelman S, Dorfman L, Ferguson K. Health professions students' perceptions of interprofessional relationships. Acad Med. 2002;77(4):354-357. [PMID: 11953306]

32. Cyr J. The unique utility of focus groups for mixed-methods research. PS: Political Science \& Politics. 2017;50(4):10381042.

33. Phillippi J, Lauderdale J. A guide to field notes for qualitative research: Context and conversation. Qual Health Res. 2018;28(3):381-388. doi: 10.1177/1049732317697102. [PMID: 29298584]

34. Lincoln Y, Guba E. Naturalistic inquiry. Newbury Park: Sage Publishing; 1985.

35. Lopez KA, Willis DG. Descriptive versus interpretive phenomenology: Their contributions to nursing knowledge. Qual Health Res. 2004;14(5):726-735. doi: 10.1177/1049732304263638. [PMID: 15107174]

36. Hulen E, Edwards ST, Poppe AP, Singh MK, Shunk R, Tuepker A. Creating change, challenging structure: Graduate and faculty perspectives on the implementation of an interprofessional education program in veterans affairs primary care. $J$ Interprof Care. 2019:1-7. doi: 10.1080/13561820.2019.1676706. [PMID: 31696759]

37. Selten EMH, Vriezekolk JE, Nijhof MW, et al. Barriers impeding the use of non-pharmacological, non-surgical care in hip and knee osteoarthritis: The views of general practitioners, physical therapists, and medical specialists. J Clin Rheumatol. 2017;23(8):405-410. doi: 10.1097/RHU.0000000000000562. [PMID: 28926466]

38. Tepper MC, Taneja E, King KM. Planning together: Patient-centered care planning to improve health outcomes. Healthcare. 2019;7(4):pii: S2213-0764(18)30065-4. doi: 10.1016/j.hjdsi.2018.12.006. [PMID: 30765318]

39. Allan HT, Smith P, O'Driscoll M. Experiences of supernumerary status and the hidden curriculum in nursing: A new twist in the theory-practice gap? J Clin Nurs. 2011;20(5-6):847-855. doi: 10.1111/j.1365-2702.2010.03570.x. [PMID: 21320207]

40. Dutton LL, Sellheim DO. The informal and hidden curriculum in physical therapist education. J Phys Ther Educ. 2014;28(3):50-63. 
Appendix A

Readiness for Interprofessional Learning Scale (RIPLS) Questionnaire

The purpose of this questionnaire is to examine the attitude of health and social care students and professionals towards interprofessional learning.

Your name: (develop your own 'personal code' by using the following formula):

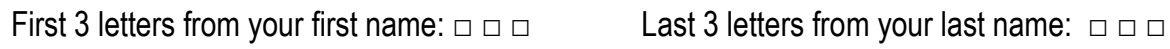

Year of birth: 19 ㅁ Your discipline:

Have you completed the RIPLS questionnaire before? $\square$ Yes $\square$ No

Gender: $\square \mathrm{M} \square \mathrm{F}$

If you answered yes to the previous question please indicate how long ago you last completed the questionnaire:
$\square 1-3$ months
$\square 3-6$ months
$\square 6-12$ months
$\square 1-2$ years
$\square$ 2-3 years
$\square 3+$ years

Have you had previous experience of interprofessional teaching? $\square$ Yes $\square$ No If you answered yes to the previous question please give a very brief statement of what this IPE teaching was and any impact it may have had.

Please complete the following questionnaire.

\begin{tabular}{|c|c|c|c|c|c|c|}
\hline & & $\begin{array}{l}\text { Strongly } \\
\text { agree }\end{array}$ & Agree & Undecided & Disagree & $\begin{array}{l}\text { Strongly } \\
\text { disagree }\end{array}$ \\
\hline 1. & $\begin{array}{l}\text { Learning with other students / } \\
\text { professionals will make me a more } \\
\text { effective member of a health and social } \\
\text { care team }\end{array}$ & & & & & \\
\hline 2. & $\begin{array}{l}\text { Patients would ultimately benefit if health } \\
\text { and social care students / professionals } \\
\text { worked together }\end{array}$ & & & & & \\
\hline 3. & $\begin{array}{l}\text { Shared learning with other health and } \\
\text { social care students / professionals will } \\
\text { increase my ability to understand clinical } \\
\text { problems }\end{array}$ & & & & & \\
\hline 4. & $\begin{array}{l}\text { Communications skills should be learned } \\
\text { with other health and social care } \\
\text { students / professionals }\end{array}$ & & & & & \\
\hline 5. & $\begin{array}{l}\text { Team-working skills are vital for all health } \\
\text { and social care students / professionals } \\
\text { to learn }\end{array}$ & & & & & \\
\hline 6. & $\begin{array}{l}\text { Shared learning will help me to } \\
\text { understand my own professional } \\
\text { limitations }\end{array}$ & & & & & \\
\hline 7. & $\begin{array}{l}\text { Learning between health and social care } \\
\text { students before qualification and for } \\
\text { professionals after qualification would } \\
\text { improve working relationships after } \\
\text { qualification / collaborative practice. }\end{array}$ & & & & & \\
\hline 8. & $\begin{array}{l}\text { Shared learning will help me think } \\
\text { positively about other health and social } \\
\text { care professionals }\end{array}$ & & & & & \\
\hline 9. & $\begin{array}{l}\text { For small-group learning to work, } \\
\text { students / professionals need to respect } \\
\text { and trust each other }\end{array}$ & & & & & \\
\hline
\end{tabular}




\begin{tabular}{|c|c|c|c|c|c|c|}
\hline & & $\begin{array}{l}\text { Strongly } \\
\text { agree }\end{array}$ & Agree & Undecided & Disagree & $\begin{array}{l}\text { Strongly } \\
\text { disagree }\end{array}$ \\
\hline 10. & $\begin{array}{l}\text { I don't want to waste time learning with } \\
\text { other health and social care students / } \\
\text { professionals }\end{array}$ & & & & & \\
\hline 11. & $\begin{array}{l}\text { It is not necessary for undergraduate / } \\
\text { postgraduate health and social care } \\
\text { students / professionals to learn together }\end{array}$ & & & & & \\
\hline 12. & $\begin{array}{l}\text { Clinical problem solving can only be } \\
\text { learnt effectively with students / } \\
\text { professionals from my own school / } \\
\text { organisation }\end{array}$ & & & & & \\
\hline 13. & $\begin{array}{l}\text { Shared learning with other health and } \\
\text { social care professionals will help me to } \\
\text { communicate better with patients and } \\
\text { other professionals }\end{array}$ & & & & & \\
\hline 14. & $\begin{array}{l}\text { I would welcome the opportunity to work } \\
\text { on small group projects with other health } \\
\text { and social care students / professionals }\end{array}$ & & & & & \\
\hline 15. & $\begin{array}{l}\text { I would welcome the opportunity to share } \\
\text { some generic lectures, tutorials or } \\
\text { workshops with other health and social } \\
\text { care students / professionals }\end{array}$ & & & & & \\
\hline 16. & $\begin{array}{l}\text { Shared learning and practice will help me } \\
\text { clarify the nature of patients' or clients' } \\
\text { problems }\end{array}$ & & & & & \\
\hline 17. & $\begin{array}{l}\text { Shared learning before and after } \\
\text { qualification will help me become a better } \\
\text { team worker }\end{array}$ & & & & & \\
\hline 18. & $\begin{array}{l}\text { I am not sure what my professional role } \\
\text { will be / is }\end{array}$ & & & & & \\
\hline 19. & $\begin{array}{l}\text { I have to acquire much more knowledge } \\
\text { and skill than other students / } \\
\text { professionals in my own faculty / } \\
\text { organisation }\end{array}$ & & & & & \\
\hline
\end{tabular}




\section{Appendix B}

Interdisciplinary Education Perception Scale

Using the scale below, (Strongly Disagree-1 to Strongly Agree-6) please rate your perception of your profession and other disciplines.

\begin{tabular}{|c|c|c|c|c|c|c|}
\hline DESCRIPTOR & $\begin{array}{l}\text { Strongly } \\
\text { Disagree } \\
1\end{array}$ & \begin{tabular}{|l} 
Moderately \\
Disagree \\
2
\end{tabular} & $\begin{array}{l}\text { Somewhat } \\
\text { Disagree } \\
3\end{array}$ & $\begin{array}{c}\text { Somewhat } \\
\text { Agree } \\
4\end{array}$ & $\begin{array}{c}\text { Moderately } \\
\text { Agree } \\
5\end{array}$ & $\begin{array}{l}\text { Strongly } \\
\text { Agree } \\
6\end{array}$ \\
\hline $\begin{array}{l}\text { 1. Individuals in my profession are well- } \\
\text { trained. }\end{array}$ & & & & & & \\
\hline $\begin{array}{l}\text { 2. Individuals in my profession are able } \\
\text { to work closely with individuals in other } \\
\text { professions. }\end{array}$ & & & & & & \\
\hline $\begin{array}{l}\text { 3. Individuals in my profession } \\
\text { demonstrate a great deal of } \\
\text { autonomy. }\end{array}$ & & & & & & \\
\hline $\begin{array}{l}\text { 4. Individuals in other professions } \\
\text { respect the work done by my } \\
\text { profession. }\end{array}$ & & & & & & \\
\hline $\begin{array}{l}\text { 5. Individuals in my profession are very } \\
\text { positive about their goals and } \\
\text { objectives. }\end{array}$ & & & & & & \\
\hline $\begin{array}{l}\text { 6. Individuals in my profession need to } \\
\text { cooperate with other professions. }\end{array}$ & & & & & & \\
\hline $\begin{array}{l}\text { 7. Individuals in my profession are } \\
\text { very positive about their contributions } \\
\text { and accomplishments. }\end{array}$ & & & & & & \\
\hline $\begin{array}{l}\text { 8. Individuals in my profession must } \\
\text { depend upon the work of people in } \\
\text { other professions. }\end{array}$ & & & & & & \\
\hline $\begin{array}{l}\text { 9. Individuals in other professions } \\
\text { think highly of my profession. }\end{array}$ & & & & & & \\
\hline $\begin{array}{l}\text { 10. Individuals in my profession trust } \\
\text { each other's professional judgment. }\end{array}$ & & & & & & \\
\hline $\begin{array}{l}\text { 11. Individuals in my profession have } \\
\text { a higher status than individuals in } \\
\text { otherprofessions. }\end{array}$ & & & & & & \\
\hline $\begin{array}{l}\text { 12. Individuals in my profession make } \\
\text { every effort to understand the } \\
\text { capabilities and contributions of other } \\
\text { professions. }\end{array}$ & & & & & & \\
\hline $\begin{array}{l}\text { 13. Individuals in my profession are } \\
\text { extremely competent. }\end{array}$ & & & & & & \\
\hline $\begin{array}{l}\text { 14. Individuals in my profession are } \\
\text { willing to share information and } \\
\text { resources with other professionals. }\end{array}$ & & & & & & \\
\hline $\begin{array}{l}\text { 15. Individuals in my profession } \\
\text { have good relations with people in } \\
\text { other professions. }\end{array}$ & & & & & & \\
\hline $\begin{array}{l}\text { 16. Individuals in my profession think } \\
\text { highly of other related professions. }\end{array}$ & & & & & & \\
\hline $\begin{array}{l}\text { 17. Individuals in my profession work } \\
\text { well with each other. }\end{array}$ & & & & & & \\
\hline $\begin{array}{l}\text { 18. Individuals in other professions } \\
\text { often seek the advice of people in my }\end{array}$ & & & & & & \\
\hline
\end{tabular}




\begin{tabular}{|c|c|c|c|c|c|c|}
\hline DESCRIPTOR & $\begin{array}{c}\text { Strongly } \\
\text { Disagree } \\
1\end{array}$ & $\begin{array}{c}\text { Moderately } \\
\text { Disagree } \\
2\end{array}$ & $\begin{array}{c}\text { Somewhat } \\
\text { Disagree } \\
3\end{array}$ & $\begin{array}{c}\text { Somewhat } \\
\text { Agree } \\
4\end{array}$ & $\begin{array}{c}\text { Moderately } \\
\text { Agree } \\
5\end{array}$ & $\begin{array}{c}\text { Strongly } \\
\text { Agree } \\
6\end{array}$ \\
\hline profession. & & & & & & \\
\hline
\end{tabular}

Appendix C

Interview guide

Thank you for agreeing to participate in this focus group. The purpose of this session is to understand your perspective on interprofessional collaboration between occupational and physical therapy practitioners. We will be asking you a series of questions related to interprofessional practice and your experience participating in the simulated case scenarios. We encourage you to be honest and express your own thoughts. This may include both positive and negative accounts. We are here to learn from you and your experience. Your responses will be used solely for the purpose of this research study and will not be shared with anyone outside of this research study, including your professors and classmates; all information gathered in this focus group will be synthesized and presented as group findings. We ask that you respect the privacy of your peers and keep any information shared during this session confidential. This session will be video recorded. Only the Pls will have access to the recordings. We want to hear from everyone. We appreciate all of your input and perspective and we want to give everyone the opportunity to speak so please refrain from interrupting the other participants. Do you have any questions before we begin?

1. How do you define interprofessional practice?

2. Compare the interprofessional simulated experience to more traditional classroom case presentations?

3. Did this simulated learning experience impact your perception of your own role and the role of the other profession?

4. Describe your perceived confidence in your professional role during the simulation.

5. Reflect and comment on the value of interprofessional training?

6. Now that you have been to the clinic, describe your interprofessional encounters/experiences and the value to you and the patient.

7. How did this experience impact your perception/confidence/performance in the clinic? 